\title{
LA ALCORAYA: UN ESPACIO HISTÓRICO AGRÍCOLA Y VIAL
}

Por

ENEIDA GARCIA GARIJO

\section{Introducción}

El estudio de la evolución histórica de La Alcoraya, --que es una de las partidas pertenecientes al municipio de Alicante - constituyó nuestro trabajo de Licenciatura defendido en noviembre de 1986. Con el resumen que a continuación vamos a exponer, pretendemos dar una visión a grandes rasgos, de la importancia que ha tenido a lo largo de su historia, tanto el espacio físico en sí mismo, como por la relación mantenida con la capital.

Nuestro esquema de trabajo, partió del análisis filológico del topónimo Alcoraya, lo que llevó posteriormente, a un estudio más amplio sobre el poblamiento de esta área, desde la antigüedad a nuestros dias. Analizamos por tanto, las fuentes literarias, arqueológicas, geográficas y planimétricas que nos ofrecían información sobre la zona, y el estudio quedó configurado por siete grandes apartados relacionados con: el medio físico llocalización, hidrología, relieve, geología económica...); la toponimia (análisis de los topónimos Alcoraya, el Campello, Celeret...); el camino como vía de comunicación desde época romana a la actualidad; el agua lorígenes, localización y distribución, sistemas de riego, cultivos...); los principales restos arqueológicos situados en La Alcoraya y Font-Calent y las conclusiones. Tras este séptimo apartado, se incluye un anexo con el material documental, compuesto por mapas que recogen la zona estudiada desde el s. XVI hasta finales del s. XIX, fuentes archivísticas y bibliográficas, pianimetría actual y material fotográfico.

\section{Toponimia}

Iniciamos el análisis filológico por el topónimo "la-Alcoraya». Partimos de que se trata de un nombre árabe o arabizado ya que el estar precedido del artículo/al/, así nos lo indica. Esto implica por tanto, la presencia de un con- 
tıngente humano más o menos numeroso, de origen musulmán en este espacio. Sobre la etimología del topónimo tenemos varias interpretaciones, entre la que destaca la que le da un origen bereber. Ésta surgió a mediados del presente siglo propuesta por C. D. Dubler y aunque puesta en duda por J. Oliver Asín, la recogió de nuevo P. Guichard y $M$. Barceló en la actualidad (M. BARCELO, 1984, 108). Nosotros creemos que lingüísticamente, se demuestra que este término no es posible, ya que los tropónimos bereberes aparecen siempre en las fuentes árabes sin artículo, y por consiguiente Alcoraya quedaría fuera de dicho grupo, debido a que lleva asimilado el artículo /al/ (M. ${ }^{a} \mathrm{~J}$. RUBIERA, 1984, 318). Otra lectura del topónimo que creemos es la corecta, sitá su origen en un nombre común árabe. Este nombre a su vez tendría dos posibles interpretaciones: una como el diminutivo de Alqarya ( ¿), i ji l, cuyo significado sería el de "pequeña población agrícola» (CORRIENTË, 1977 , 110; E. LLOBREGAT, 1984, 238; M. ${ }^{a}$ J. RUBIERA, 1985, 16) y un segundo como la palabra árabe Qaría ( $\ddot{i}$ c, $(\because)$ ) que precedida del artículo /al/ se convierte en Al-Qārica y cuyo signifícado es el de "centro de la calzada" (CORRIENTE, 1977, 110). El diminutivo de esta palabra es también Al-Qurayica

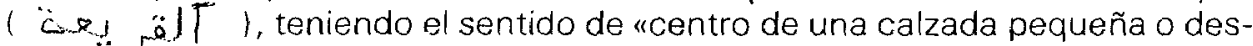
viación cle otra que se considera principal".

Existen dentro de esta misma área otros topónimos interesantes, conservados tanto por referencias en fuentes escritas, como geográficas. Entre los primeros destacaríamos Celeret. Ésta es una mansión mencionada en el Anónimo de Rávena, obra medieval, obra medieval que recopila las rutas romanas del s. Ill y las del itinerario Antonino. Por un fenómeno lingǘstico denominado Metátesis, el topónimo pre-isiámico Celeret sufre una arabización y se asimila a un término con significado en este último idioma, bien como alqariyya(t) o al-qarica (t). Al segundo grupo, pertenecería el topónimo El Campello. Es el nombre de un conjunto de casas situadas a $1 \mathrm{~km}$. del núcleo poblaciones de La Alcoraya, y separado de éste por una rambla de agua que baja desde la Sierra de las Águilas (C. M. E. hoja n. ${ }^{\circ} 781$ ). Proponemos para su análisis lingüístico, la hipótesis desarrollada por el Dr. M. de Epalza y que resumimos brevemente: el origen sería el de un mozarabismo llatinismo en época árabe). Se trataría del diminutivo latino de campus. Su origen no sería ni el castellano, ni el catalán, ya que la evolución en el primero nos habría dado campito, campillo o campico y en el segundo campet. La conservación de la -o final es una característica del mozárabe o romance de Al-Andalus que se mantiene fosilizado y diferenciado en zonas catalano-parlantes como es el caso de la Horta d'Alacant. Es la diferenciación con otras lenguas románicas de la Península, permite fechar este denominativo antes de la conquista cristiana del s. XIII y seguramente antes de la del s. VIII. Su traducción sería la de "pequeño camo" ya que se trata de un diminutovo, entendiendo por "campo» el área que circunda estrictamente el espacio urbano de una ciudad.

\section{Espacio vial}

En este apartado exponemos los rasgos, que nos inducen a pensar que La Alcoraya, pudo ser importante como punto central, en una vía de comuni- 
cación que conectaba a la capital - situada en el litoral - , con el interior de la provincia. Un repaso de las primeras rutas de las que conservamos fuentes escritas, nos sitúa en época romana. La Vía Augusta es la calzada romana más próxima a nuestra área y dentro de su amplio trazado, la mansión de $A s$ pis (localizada entre las de Adello o lllici en el itinerario Antonino (ROLDÁN, $1975,52)$ es el punto de partida del recorrido que vamos a describir. Dicha mansión no se identifica con el Aspe actual (en la margen derecha del río Vinalopó), sino con el Castillo del Río (a unos $3 \mathrm{~km}$. de ésta), ya que es la única vía natural que comunica Murcia y Valencia (E. LLOBREGAT, 1973, 83; J. MOROTE, 1979), y en él, existen restos arqueológicos de época bajoimperial hasta el s. XIII (R. AZUAR, 1981).

La mansión de Aspis es el inicio del camino al que hace referencia Alcoraya, si tomamos éste en el sentido de desviación o centro de calzada secundaria. Dicho ramal conectaría directamente Lucentum con la Vía Augusta, siendo por tanto punto intermedio entre las mansiones de Aspis y Lucentum.

Otra fuente ya mencionada es la referente a Celeret, mansión situada entre Adello e llici en el Anónimo de Rávena y que podríamos asociar a Alcoraya. Hasta ahora, sólo se la ha identificado con una localidad entre Lucentum y Saetabis (ROLDÁN, 1975), aunque posteriormente se asoció con Font-Calent y la Alcoraya (E. LLOBREGAT, 1983, 238). Nosotros pensamos, que la Alcoraya sería importante como enlace de caminos, tanto a nivel físico (es el que tiene menos obstáculos en su trazado), estratégico (está protegido por varias alturas considerables, que vigilan los puntos importantes del recorridol, como topográfico (su medición nos sitúa estrictamente en el centro entre las mansiones de Aspis y Lucentum).

Las primeras fuentes islámicas para este ramal se asocian a "cAșf» (Aspe). Nos las proporciona el geógrafo al-c ${ }^{c}$ drT (s. Xl) que describe el itinerario desde Murca a Valencia (AL-CUDRI, 1965). La cita hace referencia a la "alquería de Aspe" y no al castillo (no aparece como tal hasta 1172) (R. AZUAR, $1981,55)$. La cita podría referirse a un espacio más amplio, que formara parte de la unidad económico-espacial de "Așf», pudiendo ser así, identificado con el área de nuestro estudio.

En época moderna, la Alcoraya aparece en estudios agrícolas y geográficos de la zona. También tenemos representaciones cartográficas de esta vía a mediados del s. XVII. En el s. XIX adquiere gran popularidad por sus nacimientos de agua, que tras un proyecto de "traida de aguas desde La Alcoraya a Alicante» por D. Pardo Jimeno en 1881, abastece a la capital más de veinte años sin interrupción. También debemos destacar que el camino que seguía el agua hasta la ciudad, era conocido por uel viejo camino de la Alcoraya a Alicanten (FIGUERAS PACHECO, 1920), siendo éste, el trazado al que nosotros hacemos referencia. 


\section{Espacio agricola}

De la Alcoraya tenemos noticias, que nos la describen como una de las zonas especialmente favorables para el cultivo dentro del secano por su riqueza de agua. En 1428 hay noticias sobre reparaciones de azudes en la zona (f. A. de AROUES JOVER, 1966). También existían dos acueductos medievales desaparecidos con la riada de 1982.

En toda la partida hay muestras de su riqueza acuifera y del aprovechamiento que de ella se hace en la actualidad. Únicamente en la alquería que da nombre a la partida, tenemos numerosos elementos relacionados con el agua como: 1 algibe, 4 balsas, 1 lavadero y 2 minas que horaban la roca de la montaña más de $130 \mathrm{~m}$. de profundidad.

Ya hemos mencionado en el anterior apartado, la importancia que dicho acuífero tuvo en el siglo pasado para la ciudad de Alicante, aunque no fue la única que recibió sus aguas ya que también Elche se abasteció de ellas desde 1889 hasta 1923.

El estado actual de las fuentes y minas no nos permiten afirmar que sea obras medievales, aunque su origen pudiera ser árabe. Sabemos que son depósitos de agua explotados desde antiguo, por lo que no es de extrañar que sufriera transformaciones, que hicieran desaparecer con las primitivas construcciones por otras más recientes, que reutilizaran los materiales iniciales. Esto sucede en la mina citada, ya que para la cubrición de la cañería que circla por el centro del canal, encontramos una serie de sillares en el centro y laterales que se alternan con ladrillos de hormigón.

Si a las condiciones físicas ya descritas, unimos lo explicado en el apartado de topónimos, o sea su origen árabe más la perduración del mozarabismo "El Campello" - como perduración del ager romano-, podemos pensar que un pequeño núcleo poblacional se estableció en esta área, configurando una alquería islámica en época medieval, que evoluciona perdurando hasta nuestros días.

\section{Restos arqueológicos}

A lo largo de este itinerario, encontamos huellas arqueológicas de época romana. Hemos de destacar los restos de la villa, situada en la loma a espaldas del caserío de la Alcoraya. También la instalación bajo-imperial localizada en la Sierra de Font-Calent v que llega al s. VII d. C. (E. LLOBREGAT, 1977). En la misma sierra se encuentra los restos de dos torreones (uno casi derruido y el segundo de $2,60 \mathrm{~m}$. de altura), que por su factura podemos decir que son medievales. 


\section{Conclusión}

Partimos del estudio del topónimo Alcoraya cuyo análisis lingüístico nos da su origen árabe y un doble significado. Por un lado, el de alquería como pequeña entidad agrícola; y por otro el del centro de un camino pequeño o ramal de desviación de otro considerado principal.

Un primer contacto con el área, descubre un espacio privilegiado para el cultivo. Los terrenos son fértiles y posee agua en abundancia, dándose la circunstancia de que estos manantiales llegan a abastecer a la capital. Por tanto, es un espacio agrícola ligado a la historia de Alicante desde antiguo. Todo esto unido a la hipótesis propuesta para "El Campello" - claramente agrícola-. nos induce a pensar, que la primera traducción de Alcoraya por alquería como: pequeña entidad agrícola, tiene una base real sobre la que sustentarse.

Las favorables condiciones ya referidas, facilitaron el asentamiento desde antiguo de una población estable. Tenemos huellas arqueológicas romanas con la localización de una villa, en la que existe gran número de cerámica ibérica. Para época medieval islámica hemos descrito el topónimo, lo que implica presencia musulmana en la zona.

La continuidad como hábitat agrícola en siglos posteriores, nos viene abalado tanto por material cerámico, como por crónicas con su descripción geográfica y agrícola desde el s. XVII en adelante.

De lo dicho, deducimos que la comunicación de esta área con los espacios próximos fue fluida, lo que indica que como vía de acceso o punto de paso, reunía buenas condiciones. Fuentes documentales nos inducen a Aspis, conectaría con Lucentum. Fuentes medievales situan entre las mansiones citadas de la Celeret, que ya hemos visto que podria identificarse con la Alcoraya.

Dicho trazado está jalonado de restos arqueológicos, entre los que destaca el yacimiento visigótico y torres medievales de Font-Calent. Por último, destacar la situación estratégica de este camino, que permite una vigilancia perfecta de todo el trazado, con el control de la vía de acceso a la capital y la comunicación de ésta con el interior. Vemos como el camino se caracteriza por tener una continuidad hasta época reciente (en que es sustituido por la carretera nacional). En consecuencia, pensamos que la segunda intepretación de Alcoraya como: centro de un camino secundario, estaría justificada en este caso.

Por todo ello, creemos que se trata de un espacio importante históricamente, que pudo jugar un papel primordial, en el desarrollo de un área mucho mayor de la que hoy representa, y a la que creemos se debería prestar mayor atención y protección legal, ya que aunque se encuentra dentro de las «Áreas de importancia arqueológica del municipio de Alicanten, las industrias que se localizan actualmente en ella, aceleran su ya rápido proceso de desaparición. 


\section{BIBLIOGRAFÍA}

AL-AHWANT Editor de AL-CUDRT, Tarsic Ai-Ajbar, Madrid 1965.

ARQUES JOVER, FRAY AGUSTIN DE Nobihario Alicantino. Alicante, 1966.

ASIN PALACIOS, M. Contribución a la toponimia árabe de España. Madrid-Granada, 1944.

AZUAR RUIZ, R. Castellología medieval alicantina. Rev. Instituto de Estudios Alicantinos (IEA), Alicante, 1981.

- "Una interpretación del "Hisn" musulmán en el ámbito rural». Rev. IEA, Alicante, 1982, pp. 34-41.

- "Panorama de la arqueología de los valles altos y medio del Vinalopó (Alicanteln. LUCENTUM vol. II, Univ. Alicante. Alicante, 1983. pp. 349-383.

- "Arqueología medieval del País Valenciano y Murcia". I Jomada de Arqueología de la Univ. de Alicante. Elche, 1983.

BARBERo, A.; VIGIL, M. La formación del Feudalismo en la Península lbérica. Ed. Crítica, 2. a ed. Barcelona, 1979.

BARCELÓ. M. "Sobre tres topónims berebers a les illes orientals d'Al-Andalus". Sobre Mayürqa, Quaderns de ca la gran cristiana/2. Paima de Mallorca, 1984, pp. 107-111.

- "De toponimia tribal i clanica bereber a les jiles orientals d'Al-Andalus". Sobre Mayüra. Ouaderns de ca la gran cristianal2. Palma de Mallorca, 1984, pp. 111-117.

BENDICHO, V. Crónica de la muy ilustre, noble y leal crudad de Alicante (1640). IEA y Excma. Diputación de Alicante, Alicante 1960

BOSWORTH, C. E. y otrcs Encyclopédie de I'slam. T.V. París, 1985.

BUTZER, K. W y otros Una alquería istámica medieval de la Sierra de Espadán. Boletín de la Soc. Castellonense de Cultura. Tomo LXI. Castellón de la Plana, 1985. pp. 305-365

DUBOIS, J. y otros Diccionario Lingǘstico. Alianza Editorial. Madrid, 1979.

EPALZA, M.; ROMÁN, J. L. Toponimia mayor y menor de la provincia de Alicante. Caja de Ahorros Provincial. Alicante, 983

EPALZA, M. "Los bereberes y ia arabización del País Valencianon. Quaderns de Filología. Univ. Valencia, 1984. pP. $91-100$

FIGUERAS PACHECO, F. Compendio Histórico de Alicante. Comisión Provincial de Monumentos de Alicante. Alicante, 1957

- Geografía del Reino de Valencia. Barceloa, 1920.

AL-ADRTST Opus Geographicum. Inst. Universitario Orientale di Napoli. Roma, fasc. $1 .^{\circ}$.

IVARS PÉREZ, J. "Unas viviendas moriscas en la Cairola (La Vall d'Ebol". SHARO AL-ANDALUS, n. ${ }^{\circ} 1$. Anales de la Univ. de Alicante, 1984. pp. 91-103.

LLOBREGAT CONESA, E. Teodomiro de Oriola, su vida y su obra. Caja de Ahorros Provinciai. Alicante, 1973

- "Catastro romano de la Provicia de Alicanten. Estudio sobre centuriaciones romanas en España. Univ. Autónoma de Madrid, 1974.

- "La primitiva cristiandad valenciana. L'estel. Valencia, 1977.

- Nuestra historia. Vol III. Valencia, 1980

- «Relectura del Ravennate. Dos calzadas, una mansión inexistente y otros datos de la geografía antigua del País Valenciano". LUCENTUM, vol. II. Univ. Alicante. Alicante, 1983. pp. 225-241.

- "La perduación de un topónimo de la Vía Augusta: Lubricatum/Rahal al-Lobregati/Tumis de Lupricato».

- SHARO AL-ANDALUS. n. ${ }^{\circ}$. Anales de la Univ. de Alicante. Alicante, 1984. pp. 103-109.

MOROTE, J. G. «El trazado de la Vía Augustá desde Tarracone a Carthagine Spartaria». SAGUNTUM. PLAV 1979, pp. $141-i 59$

OLIVER-ASIN, J. Historia del nombre de Madrid. Arbor, XXVIII, 1954.

POCKLINGTON, R. "Vestigios de la antigua toponímia mozárabe de la huerta y campo de Murcia». (En prensa).

ROSSELLO, V. M. "Restos del catastro romano en Caudete y Villenam. Estudios Geográficos. Madrid 1980, pp. 5-13.

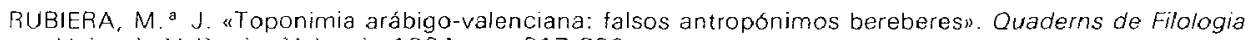
Univ. de València, Valencia 1984. pp. 317-320.

- La Taifa de Denia. inst. Gil Albert, Excma. Dip. Prov. Alicante 1985

- Villena en la calzada romana y árabe. Ayuntamiento de Villena, Univ. Alicante, 1985.

SILLIERES, P. uLe camino de Anibal». Itineraire des gobelets de Vicarello de Castulo a Saetabis". Melanges de la Casa de Velázquez. N. ${ }^{\circ}$ XIII, 1977. pp. 31-81.

TORRES BALBAS, L. "La Vía Augusta y el arrecife musulmán». AL-ANDALUS, vol. XXIV 1959. pp. 441-448 